\title{
Design Consideration for High Power Density GaN Buck-Rectifier in ISOP-IPOS Converter based dc Distribution System
}

\author{
Yusuke Hayashi ${ }^{1}$, Hiroshi Iso ${ }^{1}$, Daisuke Hara ${ }^{1}$ and Akira Matsumoto ${ }^{2}$ \\ 1. Division of Electrical, Electronic and Information Engineering, Graduate School of Engineering, Osaka University, Osaka \\ 5650871, Japan \\ 2. Research and Department Headquarters, NTT (Nippon Telegraph and Telephone) Facilities, Inc. (Incorporated), Tokyo 1700004, \\ Japan
}

Received: March 17, 2015 / Accepted: May 04, 2015 / Published: June 30, 2015.

\begin{abstract}
GaN (gallium nitride) buck-rectifier has been proposed to realize high power density ISOP (input series and output parallel)-IPOS (input parallel and output series) converter-based de distribution system. The ultra-low loss bi-directional switch can be developed by the GaN power device because of the low on-resistance, the high-speed switching behavior and its own device structure. The buck-rectifier using the GaN bi-directional switches has the potential to achieve higher power density than the commonly utilized boost-rectifier. Availability of the GaN-HEMT (high electron mobility transistor) for the buck rectifier has been verified taking the theoretical limit of the on-resistance and the switching loss energy into account. Design consideration for a high power density buck-rectifier has been also conducted and the application effect of the GaN bidirectional switches has been evaluated quantitatively. The ISOP-IPOS converter-based dc (direct current) distribution system takes full advantage of the buck-rectifier and the rectifier using $\mathrm{GaN}$ devices contributes to realizing higher power density dc distribution system.
\end{abstract}

Key words: ac (alternate current)-dc converter, GaN (gallium nitride) power device, power density, dc distribution, ISOP-IPOS topology.

\section{Introduction}

The amount of network traffic in the data centers has recently been rapidly increasing due to the widespread use of ICT (information and communication technology) equipment $[1,2]$. Energy and resource savings in data centers will contribute to solving some of our global environmental problems. The NTT (Nippon Telegraph and Telephone) Group has been proposing next generation dc distribution system that goes beyond the conventional $380 \mathrm{~V}$ dc (direct current) distribution system to realize highly efficient and space saving (high power density) power

Corresponding author: Yusuke Hayashi, Ph.D., research fields: DC distribution system, DC power supply and power electronics system integration. E-mail: y_hayashi@pe.eei.eng.osaka-u.ac.jp. supply system [3-5].

There are mainly two key issues to develop the high power density power supply system as follows:

- High power density and high TF (transfer factor) dc-dc power converters to reduce the number of power conversion stages in the dc distribution system;

- Highly efficient and ultra-compact front-end ac (alternate current)-dc power converters for the ac interface.

To solve the first issue, the multi-cell converter topology has been already proposed [6]. The proposed topology is based on the ISOP (input series and output parallel)-IPOS (input parallel and output series) connections of highly integrated isolated dc-dc converter modules. The $384 \mathrm{~V}$ to $12 \mathrm{~V} \mathrm{dc}$-dc converter with the power density of $10 \mathrm{~W} / \mathrm{cm}^{3}$ has been 
fabricated and the potential to improve the total power density in the dc distribution system has been also reported [7]. Now, the high power density front-end ac-de converter is indispensable.

In this paper, the ac-dc buck converter (buck-rectifier) using GaN (gallium nitride) power devices has been proposed taking the ISOP-IPOS converter-based dc distribution system into account. Novel power devices as $\mathrm{SiC}$ (silicon carbide) and $\mathrm{GaN}$ realize the low loss bi-directional switch because of their ultra-low specific on-resistances, and the ultra-low loss GaN bi-directional switch has been reported [8]. The buck converter using $\mathrm{GaN}$ bi-directional switches has the potential to achieve higher power density compared with the commonly utilized ac-dc boost converter (boost-rectifier).

In chapter 2, the configuration of the next generation dc distribution system and its features are introduced. In chapter 3, the buck-rectifier using GaN power devices is presented and the characteristics of the GaN power device is described taking its theoretical limit of the on-resistance and the switching behavior into account. In chapter 4, the design consideration for a high power density buck-rectifier is conducted. The estimated power density and the efficiency are compared with the performances of the boost-rectifier, and the potential to accomplish higher power density is shown.

\section{Next Generation de Distribution System}

\subsection{Conventional 380 V dc Distribution System}

Fig. 1 shows the schematic block diagram of the already developed $380 \mathrm{~V}$ dc distribution system in NTT [9]. The rectifier supplies dc $380 \mathrm{~V}$ to the ICT loads, and this consists of the ac-dc converter and the isolated dc-dc converter here. The efficiency of the rectifier is now at a level of $95.0 \%$. In the ICT equipment, dc-dc converters such as the PSU (power supply unit), the bus converter and the POL (point of load) converter are generally installed. These conversion efficiencies are e.g., 95.0\%, 97.0\% and $91.0 \%$ from the published datasheets, respectively, and the total efficiency is estimated to be $83.9 \%$. The $380 \mathrm{~V}$ $\mathrm{dc}$ distribution system has five conversion stages from the ac input terminal to the ICT loads such as the memories, CPUs (central processing units) and HDDs (hard disk drives), stepping down the dc voltage gradually.

\subsection{Nextgeneration dc Distribution System}

Fig. 2 shows the schematic block diagram of the next generation dc distribution system [5]. To achieve higher power density, the number of the conversion stage has been reduced compared with the conventional $380 \mathrm{~V}$ dc distribution system. The dc voltage is strictly controlled by the rectifier which consists of the front-end ac-dc converter. The delivered dc power is insulated at the isolated dc-dc converter and the input dc voltage of the converter is stepped down to connect ICT loads with high TF. High power density with high TF dc-dc converter and the high power density ac-dc converter play an important role in realizing next generation dc distribution system.

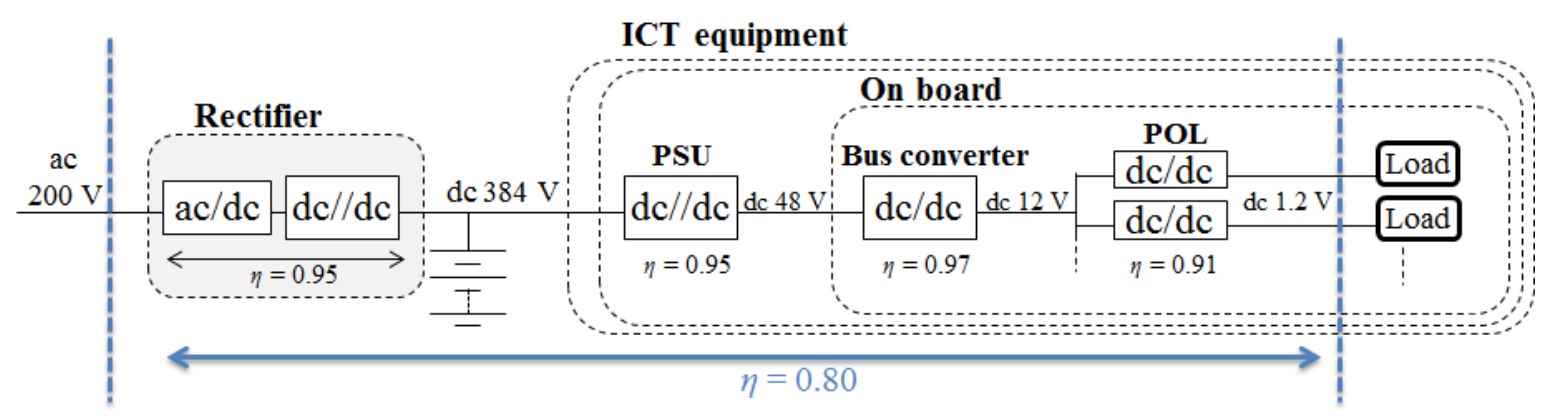

Fig. 1 Configuration of conventional $380 \mathrm{~V}$ dc distribution system. 


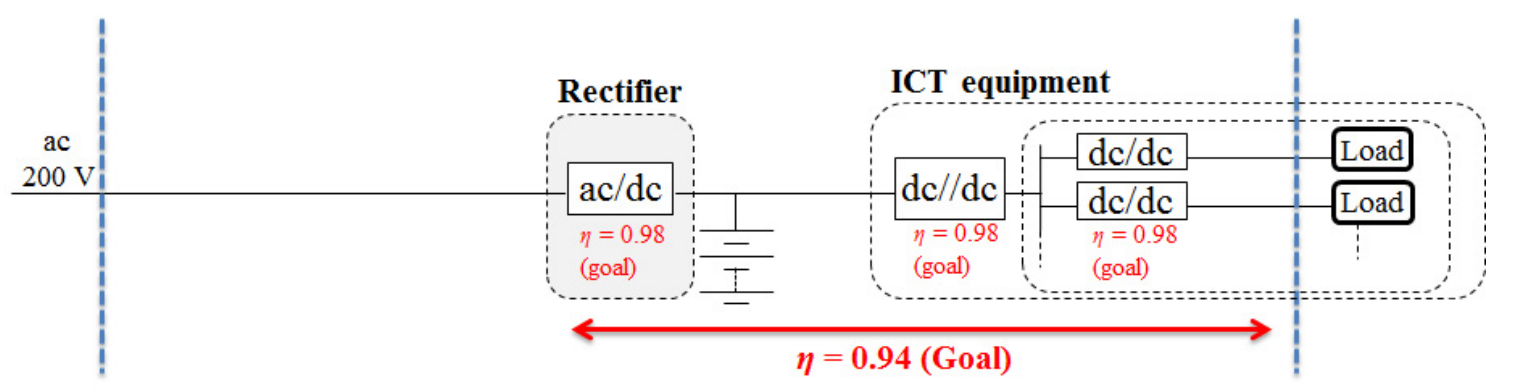

Fig. 2 Configuration of next generation de distribution system.

\subsection{ISOP-IPOS Topology in Next Generation dc} Distribution System

Multi-cell converter approach has been already proposed to achieve high power density and high $\mathrm{TF}$ isolated dc-dc converter shown in Fig. 2 [6]. Multi-cell converter approach means the ISOP and IPOS connection topology of highly integrated isolated dc-dc converter modules. Fig. 3 shows the schematic diagram of the proposed approach and the features are summarized as follows:

- The I/O (input and the output) voltages of the developed dc-dc converter are selectable and these are equal to the integral multiple of the $\mathrm{I} / \mathrm{O}$ voltages of the single cell module, respectively;

- The power density and the efficiency of the developed dc-dc converter which consists of the cell converter modules are determined by a single cell module as shown in Eqs. (1) and (2):

$$
\begin{gathered}
\eta_{C}=\frac{P_{o C}}{P_{i C}}, \eta_{T}=\frac{P_{o T}}{P_{i T}}=\frac{P_{o C} \times N}{P_{i C} \times N}=\eta_{C} \\
D_{p C}=\frac{V o l_{C}}{P_{o C}}, D_{p T}=\frac{V o l_{T}}{P_{T C}}=\frac{V o l_{C} \times N}{P_{o C} \times N}=D_{p C}
\end{gathered}
$$

where, $\eta$ and $D_{p}$ mean the conversion efficiency and the power density, respectively; the input and the output powers are $P_{i}$ and $P_{o}$, respectively; the symbol of $\mathrm{Vol}$ means the converter volume; the subscripts of $C$ and $T$ are utilized for the cell converter module and the developed dc-dc converter, respectively.

A prototype of $384 \mathrm{~V}$ to $12 \mathrm{~V} \mathrm{dc}-\mathrm{dc}$ converter has been fabricated by using eight $48 \mathrm{~V}$ to $12 \mathrm{~V}$ dc-dc converter modules. The efficiency of $98.1 \%$ with the power density of $10.0 \mathrm{~W} / \mathrm{cm}^{3}$ has been achieved [7]. This means that, the aforementioned efficiency and the

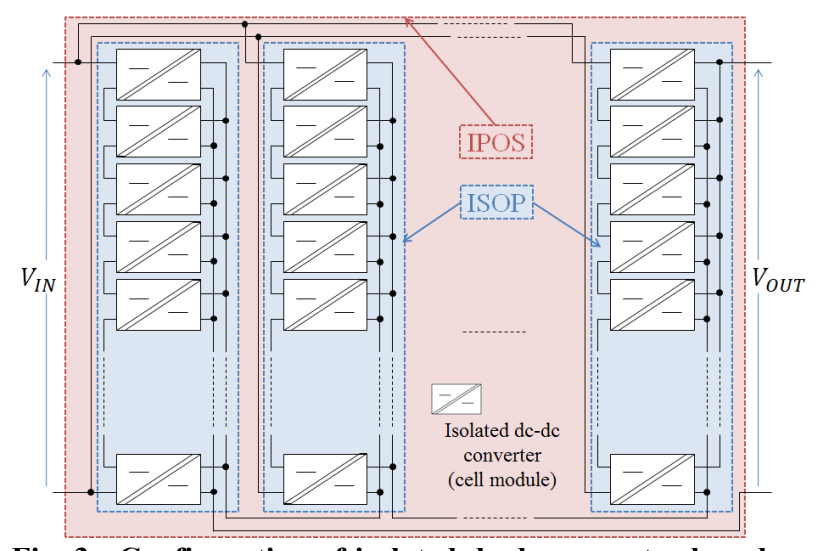

Fig. 3 Configuration of isolated dc-dc converter based on ISOP-IPOS topology.

power density can be achieved at each dc-dc conversion stage and the ac-dc converters for e.g., $200 \mathrm{~V}$ to $384 \mathrm{~V}$ and $200 \mathrm{~V}$ to $96 \mathrm{~V}$ can be installed without taking the performance of dc-dc converter into account.

The ISOP-IPOS topology expands the possibility of the ac-dc converter design. The performance of the $\mathrm{dc}-\mathrm{dc}$ converter is normalized here, and the power density of the ac-dc converter determines the total performance of the dc distribution system.

\section{GaN Power Devices for High Power Density Buck-Rectifier}

\subsection{Configuration of Rectifier}

Figs. 4 and 5 show the circuit configurations of the ac-dc converter using the boost- and the buck-rectifier, respectively in the ISOP-IPOS converter-based dc distribution system.

The boost topology is commonly utilized for the ac-dc power conversion because the buck topology requires bi-directional semiconductor switches. The 


\section{Design Consideration for High Power Density GaN Buck-Rectifier in ISOP-IPOS Converter based dc Distribution System}

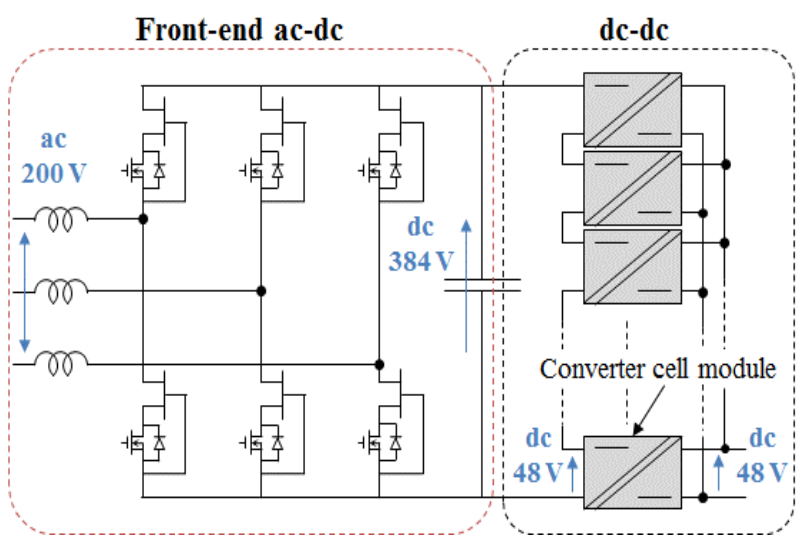

Fig. 4 Configuration of boost-rectifier and ISOP-IPOS based dc-dc converter.

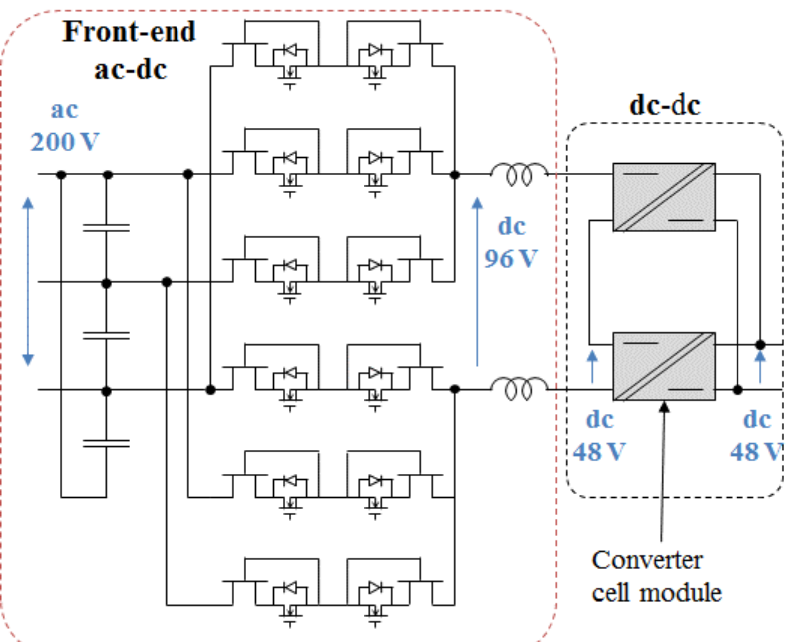

Fig. 5 Configuration of buck-rectifier and ISOP-IPOS based dc-dc converter.

bi-directional switch generally consists of single RB (reverse blocking) IGBT (insulated gate bipolar transistor), a MOSFET (metal oxide semiconductor field effect transistor) with a series connected diode or two MOSFETs connected in anti-series. The equivalent on-resistance of the bi-directional switch is generally higher than the resistance of the uni-directional transistor at the equal rated voltage and this affects the conversion loss significantly.

However, the voltage stress in the buck rectifier is lower than the stress in the boost-rectifier in the case of the same input ac voltage. The ISOP-IPOS converter-based dc distribution system eliminates the above drawback of the buck converter topology because the output voltage of ac-dc converter is selectable and this voltage does not affect the performance of dc-dc conversion stages.

\subsection{On-Resistance of Bi-directional Switch Using GaN} Power Devices

Remarkable loss reduction of semiconductor power devices has been achieved in recent years. High-speed and ultra-low loss devices as $\mathrm{SiC}$ and $\mathrm{GaN}$ are now commercially available.

The theoretical limit of the on-resistance for the unipolar power device is calculated by Eq. (3) [10]. In Eq. (3), $R_{o n} \cdot A$ means the specific on-resistance and $V_{b d}$ means the breakdown voltage of the power device; symbols of $\mu, \varepsilon_{S}$ and $E_{C}$ are the electron mobility, the permittivity and the breakdown electric field which depend on the semiconductor material, respectively.

$$
R_{o n} \cdot A=\frac{4 \cdot V_{b d}^{2}}{\mu \cdot \varepsilon_{S} \cdot E_{C}^{3}}
$$

Fig. 6 shows the theoretical limit of the specific on-resistance for $\mathrm{Si}, \mathrm{SiC}$ and $\mathrm{GaN}$ unipolar power devices. The on-resistance of the power device increases with the square of its breakdown voltage. In the case of $200 \mathrm{~V}$ to $384 \mathrm{~V}$ boost-rectifier in Fig. 4, the on-resistance of the $\mathrm{GaN}$ power device was calculated to be $17.2 \mathrm{~m} \Omega \cdot \mathrm{cm}^{2}$ at $384 \mathrm{~V}$ because of the output $\mathrm{dc}$ voltage without consideringany overshoots in the switching transient. In the case of $200 \mathrm{~V}$ to $96 \mathrm{~V}$ buck-rectifier as shown in Fig. 5, the

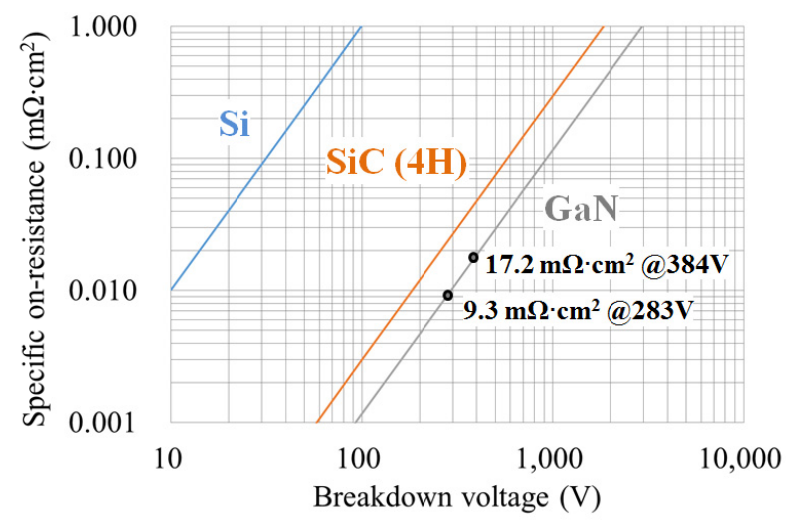

Fig. 6 Theoretical limit of specific on-resistance for $\mathrm{Si}, \mathrm{SiC}$ and GaN unipolar power devices. 
on-resistance was $9.3 \mathrm{~m} \Omega \cdot \mathrm{cm}^{2}$ at $283 \mathrm{~V}$ because of the peak value of the input ac voltage. The on-resistance of the bi-directional switch becomes $18.6 \mathrm{~m} \Omega \cdot \mathrm{cm}^{2}$ for the ac $200 \mathrm{~V}$ buck-rectifier in case two transistors are connected in anti-series. The on-resistance for the buck rectifier approaches to the resistance for the boost rectifier.

Moreover, the ultra-low loss bi-directional switch based on the GaN lateral transistor has been developed and the application effect for the matrix (ac-ac) converter has been reported [11]. The developed bi-directional switch consists of single GaN transistor and the on-resistance becomes much lower than the resistance of the switch which requires two transistors.

The specific on-resistance of the GaN power device for the buck-rectifier has the potential to be lower than the resistance for the boost rectifier. The ac-dc buck converter is a strong candidate to realize high power density dc distribution system.

\subsection{Power Loss Limit Model and Switching Behavior of GaN Power Device}

The hard-switching topology is generally applied for the ac-dc converter as shown in Figs. 4 and 5. The high-speed power device is indispensable to achieve higher power density. The power loss limit model has been already proposed to evaluate the switching energy of the high-speed power device exactly [12]. In this model, the switching loss energy is formulated as follows:

$$
\begin{gathered}
E_{S W}=E_{O N}+E_{O F F} \\
=E_{O N-t}+E_{O F F-t}+E_{\text {OSS }}+E_{\text {diode }}+E_{C S}+E_{L S} \\
E_{S W \text { (Limit) })} \cong E_{\text {oss }}+E_{\text {diode }}
\end{gathered}
$$

Eq. (4) means the switching loss energy generally consists of the time-dependent energies caused by the gate resistance $E_{O N-t}$ and $E_{O F F-t}$, the stored energy of the device output capacitance $E_{\text {oss }}$, the stored energy of the junction capacitance of the free-wheeling diode $E_{\text {diode }}$ and energies in circuit parasitic parameters $E_{L S}$ and $E_{C S}$. Eq. (5) shows the theoretical lower limit of the loss energy in the hard-switching topology. The ultra-fast switching with no gate resistance makes the time-dependent energy $E_{O N-t}$ and $E_{O F F-t}$ negligible, and the energies caused by the circuit parasitic parameters $E_{L S}$ and $E_{C S}$ approach to zero in the highly integrated circuit. The semiconductor power device whose loss energy is described in Eq. (5) is attractive for realizing high power density converter.

The characteristics of the switching loss energies of commercially available GaN-HEMT (600 V, 16 A), SiC-MOSFET (1,200 V, $33 \mathrm{~A}$ ) and Si-SJ (super junction) MOSFET $(600 \mathrm{~V}, 20 \mathrm{~A})$ were measured based on the double-pulse test under the condition that the drain to source voltage $V_{d s}$ was up to $384 \mathrm{~V}$ and the drain current $I_{d}$ was up to 20 A with no external gate resistance. The SiC-SBD (Schottky barrier diode) (600 V, 12 A) was applied for the free-wheeling diode. Fig. 7 shows the experimental apparatus of the double-pulse test and its equivalent circuit.

Fig. 8 shows the turn-off waveforms for a GaN-HEMT, and Fig. 9 shows the switching loss energies for the aforementioned devices in the case of the drain to source voltage $V_{d s}$ was $384 \mathrm{~V}$. The switching loss energies were calculated by integrating the product of $V_{d s}$ and $I_{d}$ in Fig. 8. From Fig. 9, the turn-on and the turn-off switching energies of the GaN-HEMT have the following characteristics.

- The measured switching loss energies $E_{O N}$ and $E_{O F F}$ were smaller than the loss energies generated from other candidates;

- The loss energies were constant $[13,14]$ and independent of the drain current $I_{d}$.

This means that, the high-speed switching is accomplished for GaN-HEMT and the loss energy becomes the total amount of the stored energies $E_{\text {oss }}$, and $E_{\text {diode }}$ mainly. Fig. 10 shows the total switching loss energies of the GaN-HEMT $\left(E_{O N}+E_{O F F}\right)$ and the theoretical stored energies $\left(E_{\text {oss }}+E_{\text {diode }}\right)$ in case the drain to source voltages $V_{d s}$ were $384 \mathrm{~V}$ and $192 \mathrm{~V}$. The switching loss energies of GaN-HEMT are based on the power loss limit model and this device behaves ideally in the hard-switching operation. 


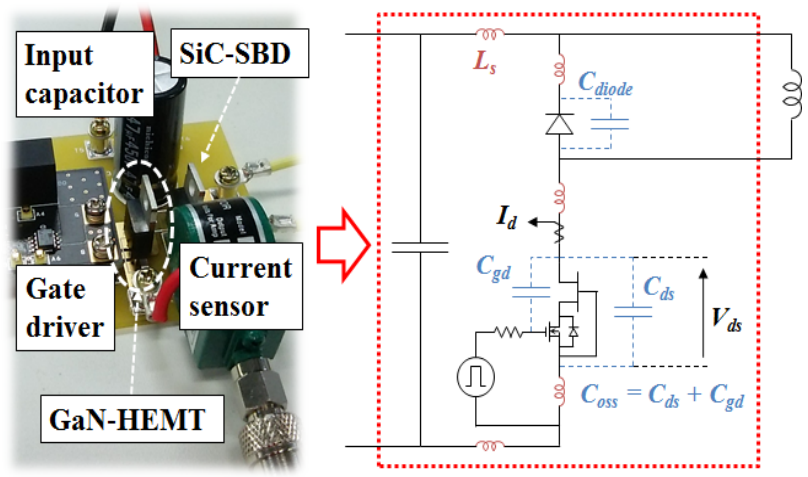

Fig. 7 Experimental apparatus and equivalent circuit for double-pulse test using GaN-HEMT and SiC-SBD.

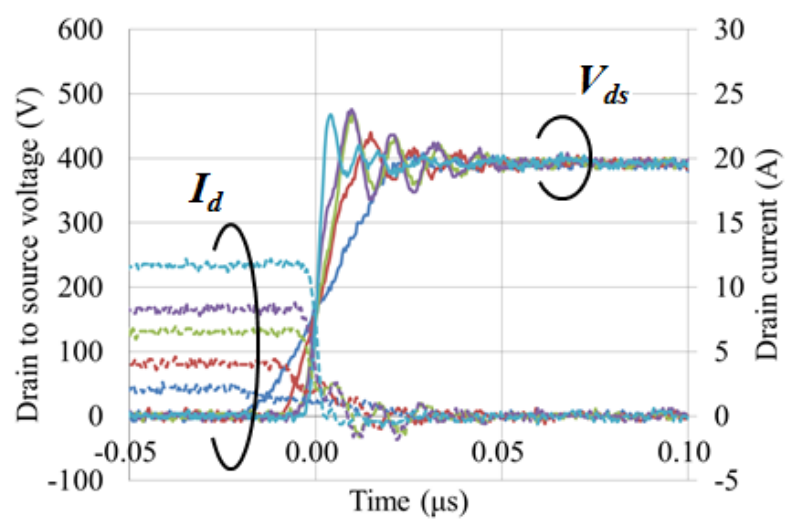

Fig. 8 Turn-off waveforms of GaN-HEMT under double pulse test $\left(V_{d s}: 384 \mathrm{~V}, I_{d}: 2-13 \mathrm{~A}\right)$.

\section{Design Consideration for High Power Density Buck-Rectifier}

\subsection{High Power Density Design Methodology}

The design methodology for high power density converters has been already proposed [15-17]. The relationship between the power density and the efficiency is essential to evaluate the barrier of power converter performance. Authors have already proposed the design methodology for realizing high power density converters $[17,18]$. Design flowchart for high power density converter is shown in Fig. 11 and the features of the design methodology are as follows:

- A power loss limit model is applied to estimate the switching loss energy generated from high-speed hard switching uni-polar power devices exactly [12]. The switching behavior of the GaN-HEMT is based on the model as shown in Fig. 10.

- A loss map is utilized to calculate the core loss

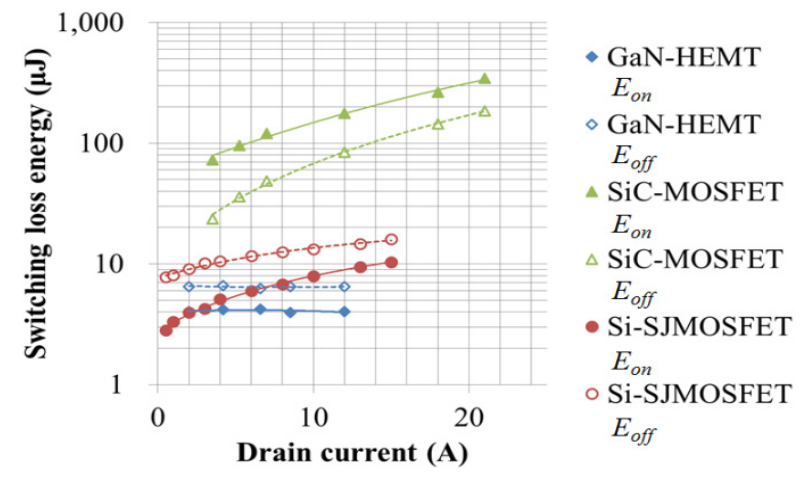

Fig. 9 Switching loss energies of GaN-HEMT, SiC-MOSFET and Si-SJMOSFET $\left(V_{d s}=384 \mathrm{~V}\right)$.

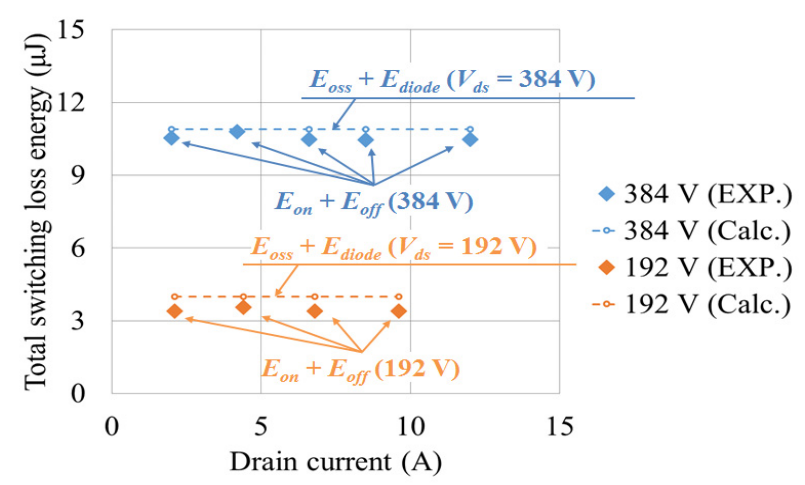

Fig. 10 Experimental switching loss energies of GaN-HEMT and theoretical stored energies in output capacitances of power devices.

from the magnetic components [19, 20]. The loss map is the database of core loss energies related to the dynamic minor loop's areas under the real PWM (pulse width modulation) operation conditions.

- The optimization process (e.g., the downhill simplex method) is conducted by using ISIGHT software to maximize the power density and/or the efficiency. The optimal design parameters are also extracted, taking the structure design and the thermal design into account.

By means of the above methods, the total power loss from the rectifier is estimated exactly. The power density of the rectifieris calculated by estimating the heat sink volume caused by the power loss. The power density of the rectifier $D_{P}$ and the efficiency $\eta$ are estimated simply by using the following equations.

$$
\begin{aligned}
& D_{P}\left(\frac{\mathrm{W}}{\mathrm{cm}^{3}}\right)=\frac{P_{o}(\mathrm{~W})}{V o_{T}\left(\mathrm{~cm}^{3}\right)} \\
= & \frac{P_{O}}{V o_{L}+V o_{C}+V o_{H S}\left(P_{T}\right)}
\end{aligned}
$$




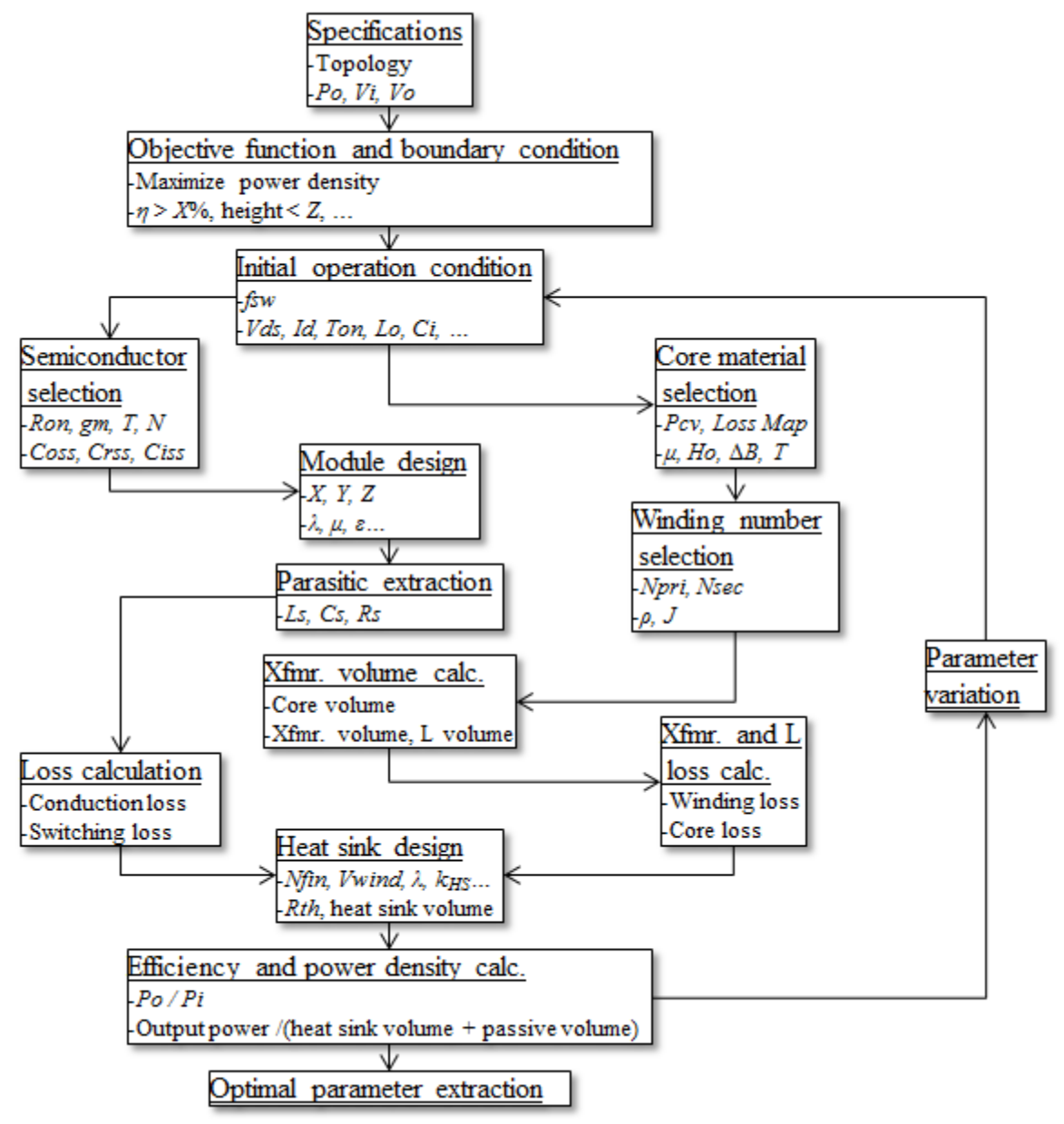

Fig. 11 Design flowchart for high power density power converter.

$$
\eta(\%)=\frac{P_{O}}{P_{O}+P_{T}} \times 100 \%
$$

The output power of the converter is $P_{O}$ and the total volume is $V_{O T}$. The total volume $V_{O T}$ consists of the volumes of the output inductor $V_{O L}$, the input capacitor $V_{O C}$ and the heat sink $V_{O H S}$. The heat sink volume $V_{O H S}$ is simply estimated as follows by using the total power loss $P_{T}$ and the heat dissipation efficiency $k_{H S}$ [21].

$$
\begin{gathered}
V o_{H S}\left(\mathrm{~cm}^{3}\right)=\frac{P_{T}(\mathrm{~W})}{k_{H S}\left(\mathrm{~W} / \mathrm{cm}^{3}\right)}=\frac{P_{Q}+P_{L o}+P_{C i}+P_{D}}{k_{H S}} \\
P_{Q}(\mathrm{~W})=P_{C O N D}+P_{S W} \\
=\left\{R_{O N} \cdot I_{i}^{2}+f_{S W} \cdot\left(E_{O N}+E_{O F F}\right)\right\} \\
P_{L O}(\mathrm{~W})=P_{C u}+P_{C O R E} \\
=\left\{R_{W} \cdot I_{O}^{2}+f_{S W} \cdot E_{C O R E}\right\} \\
P_{C i}(\mathrm{~W})=R_{C i} \cdot I_{C i}^{2} \\
P_{D}(\mathrm{~W})=V_{D} \cdot I_{i}
\end{gathered}
$$

The total power loss $P_{T}$ consists of the loss from the PWM controlled GaN-HEMT $P_{Q}$, the inductor loss $P_{L o}$, the capacitor loss $P_{C i}$ and the loss from the reverse diode of GaN-HEMT $P_{D}$. The power loss $P_{Q}$ consists of the conduction loss $P_{C O N D}$ and the switching loss $P_{S W}$. The conduction loss of the transistor $P_{C O N D}$ depends on the on-resistance $R_{O N}$ and the converter input current $I_{i}$. The turn-on and turn-off switching losses $P_{O N}$ and $P_{O F F}$ depend on the operating switching frequency $f_{S W}$, the turn-on loss energy $E_{O N}$ and turn-off energy $E_{O F F}$. The loss from the inductor $P_{L o}$ consists of the winding copper loss $P_{C u}$ and the core loss $P_{C O R E}$. The copper loss $P_{C u}$ depends on the winding resistance $R_{W}$ and the output current $I_{o}$. The core loss $P_{C O R E}$ is calculated by using the frequency $f_{S W}$ and the core loss energy $E_{C O R E}$ from the loss map [6]. The resistance $R_{C}$ means the 
ESR (equivalent series resistance) of the capacitor $C_{i}$ and the voltage $V_{D}$ shows the forward voltage drop of the reverse diode $D$.

\subsection{Power Density Evaluation for $200 \mathrm{~V}$ to $96 \mathrm{~V}$ Buck-Rectifier Using GaN Power Devices}

The power density and the efficiency are estimated by using the above design methodology for the $200 \mathrm{~V}$ to $96 \mathrm{~V}$ ac-dc buck-rectifier. The estimation result for the buck-rectifier is also compared with the estimation result for the $200 \mathrm{~V}$ to $384 \mathrm{~V}$ boost-rectifier to show the availability. The configurations for dc distribution systems using boost- and buck-rectifiers are shown in Figs. 4 and 5, respectively, and the transfer factor between the input ac voltage and the output dc voltage was determined to be approximately symmetry for these rectifiers. Table 1 shows the specifications for the rectifiers.

The input voltage was ac $200 \mathrm{~V}$ and the output voltage for the ICT loads was dc $48 \mathrm{~V}$ in the dc distribution system. For the single buck converter, the output voltage and the output power were dc $96 \mathrm{~V}$ and $600 \mathrm{~W}$, respectively. These parameters for the single boost converter were dc $384 \mathrm{~V}$ and 2,400 W. The output power for each converter depended on the number of installed converter cell modules. In this case, the 48-48 V, $300 \mathrm{~W}$ converter was assumed for the cell converter module. Eight cell modules were utilized for the $\mathrm{dc} 384 \mathrm{~V}$ boost converter and two modules were employed for the dc $96 \mathrm{~V}$ buck converter.

The power density and the efficiency can be discussed in case two rectifiers have different output powers, because the circuit configurations in Figs. 4 and 5 can be connected in parallel to expand and equalize their output powers. In this case, four buck-rectifiers were connected in parallel to equalize the output power of the boost-rectifier.

Table 2 shows the parameters for ac-dc converter design. Commercially available GaN-HEMT and $\mathrm{Fe}-\mathrm{Al}$-Si magnetic core were assumed here and the influence of the rated voltage on the on-resisntance
Table 1 Specifications for buck- and boost-rectifiers in ISOP-IPOS converter-based dc distribution system.

\begin{tabular}{lll}
\hline & Buck-rectifier & Boost-rectifier \\
\hline $\begin{array}{l}\text { Total output } \\
\text { power }\end{array}$ & $2,400 \mathrm{~W}$ & $2,400 \mathrm{~W}$ \\
Input ac voltage & ac $200 \mathrm{~W} /$ rectifier-4 sets $)$ & \\
$\begin{array}{l}\text { Dc link voltage } \\
\text { Output dc voltage } 96 \mathrm{~V}\end{array}$ & $\mathrm{dc} 48 \mathrm{~V}$ & $\mathrm{dc} 384 \mathrm{~V}$ \\
$\begin{array}{l}\text { Cell module } \\
\text { Number of cell }\end{array}$ & $48-48 \mathrm{~V}, 300 \mathrm{~W}$ & $\mathrm{dc} 48 \mathrm{~V}$ \\
modules & $8(2 /$ rectifier$\cdot 4$ sets $)$ & 8 \\
\hline
\end{tabular}

Table 2 Components' and circuit parameters for ac-dc converter design.

\begin{tabular}{ll}
\hline Components' parameters & \\
\hline Transistor $(Q)$ & $\begin{array}{l}\text { GaN-HEMT } \\
(600 \mathrm{~V}, 150 \mathrm{~m} \Omega)\end{array}$ \\
Inductor $(L o)$ & $\begin{array}{l}\text { Fe-Al-Si } \\
(\mu \mathrm{r}=50)\end{array}$ \\
\hline Design parameters & \\
\hline Switching frequency $\left(f_{S W}\right)$ & $10-100 \mathrm{kHz}$ \\
No. of transistors in parallel $\left(N_{Q}\right)$ & $1-10$ \\
Bias magnetic field of $L o$ & $<5,000 \mathrm{~A} / \mathrm{m}$ \\
Magnetic flux density of $L o$ & $<150 \mathrm{mT}$ \\
Current density of windings in $L o$ & $3.0 \mathrm{~A} / \mathrm{mm}^{2}$ \\
Heat dissipation efficiency $\left(k_{H S}\right)$ & $0.65 \mathrm{~W} / \mathrm{cm}^{3}$
\end{tabular}

was not considered to simplify the design. The power density and the efficiency were estimated by using the aforementioned Eqs. (6) and (7) in case the switching frequency $f_{S W}$ and the number of transistors connected in parallel $N_{Q}$ were varied.

Figs. 12-14 show the calculation results of the conversion efficiencies for the ac-dc converters. The power losses generated from the transistors and the inductor were considered here. The loss from the capacitor was not considered because of the low ESR. Fig. 12 is the efficiency of the $200 \mathrm{~V}$ to $96 \mathrm{~V}$ ac-dc converter using two GaN-HEMTs for a bi-directional switch as shown in Fig. 5. In the case of $N_{Q}=1$, the on-resistance of a bi-directional switch was $300 \mathrm{~m} \Omega$ because of two $150 \mathrm{~m} \Omega$ devices. Fig. 13 shows the efficiency for the $200 \mathrm{~V}$ to $96 \mathrm{~V}$ rectifier assuming a single bi-directional $\mathrm{GaN}$ transistor [8]. Here, the on-resistance of a bi-directional switch was simply assumed to be $150 \mathrm{~m} \Omega$ in $N_{Q}=1$. Fig. 14 is the efficiency for the $200 \mathrm{~V}$ to $384 \mathrm{~V}$ converter using GaN-HEMTs shown in Fig. 4. 


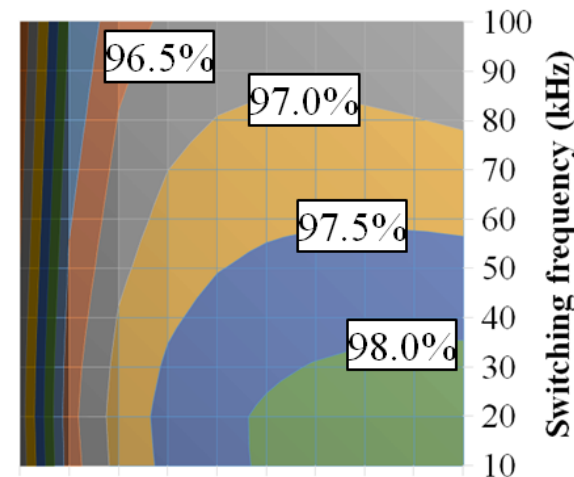

$\begin{array}{llllllllll}1 & 2 & 3 & 4 & 5 & 6 & 7 & 8 & 9 & 10\end{array}$

Transistors connected in parallel

Fig. 12 Calculated efficiency for $200 \mathrm{~V}$ to $96 \mathrm{~V}$ rectifier using two GaN transistors for a bi-directional switch.

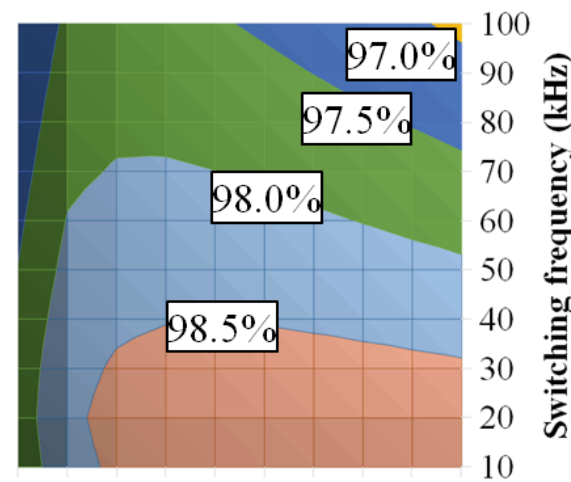

$\begin{array}{llllllllll}1 & 2 & 3 & 4 & 5 & 6 & 7 & 8 & 9 & 10\end{array}$

Transistors connected in parallel

Fig. 13 Calculated efficiency for $200 \mathrm{~V}$ to $96 \mathrm{~V}$ rectifier assuming single $\mathrm{GaN}$ bi-directional transistor.

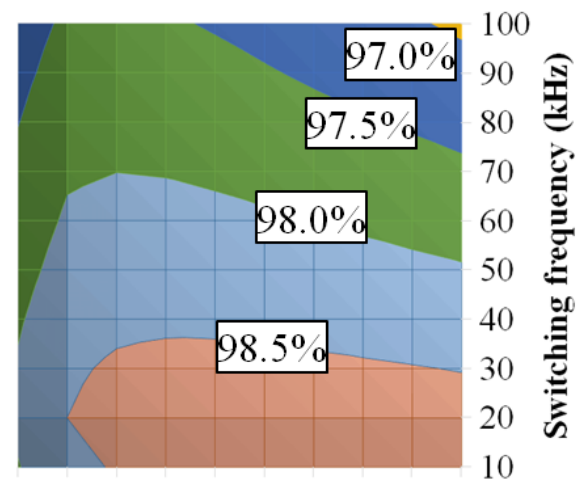

$\begin{array}{llllllllll}1 & 2 & 3 & 4 & 5 & 6 & 7 & 8 & 9 & 10\end{array}$

Transistors connected in parallel

Fig. 14 Calculated efficiency for $200 \mathrm{~V}$ to $384 \mathrm{~V}$ rectifier using GaN transistors.

Generally, the ac-dc buck converter has lower efficiency than the ac-dc boost converter because of the number of transistors as shown in Figs. 12 and 14. The

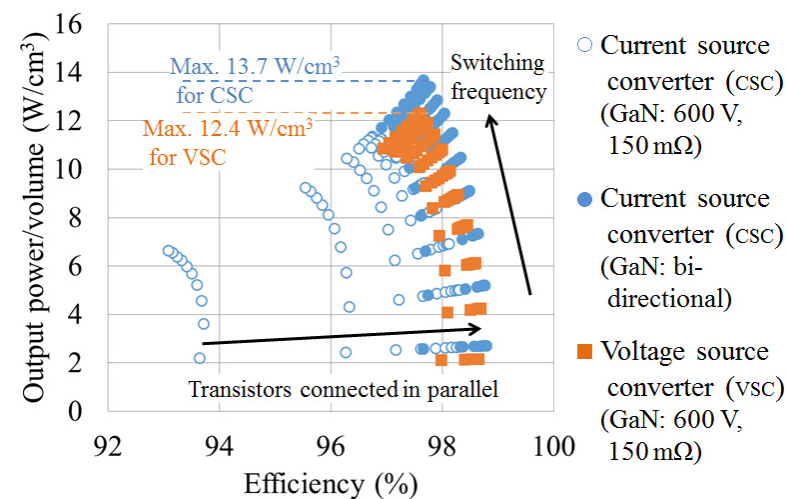

Fig. 15 Estimated power density and efficiency for buckand boost-rectifiers.

single bi-directional GaN transistor reduces the number of devices and realizes higher efficiency as shown in Figs. 12 and 13. From Figs. 13 and 14, the efficiency of the buck rectifier is approximately equal to that of the boost rectifier.

Fig. 15 shows the relationship between the power density and the efficiency for the buck- and the boostrectifiers. Volumes generated from the inductor and the heat sink were considered here. The heat sink volume was estimated simply by using the heat dissipation efficiency $k_{H S}$ of $0.65 \mathrm{~W} / \mathrm{cm}^{3}$ taking the forced-air cooling in data centers into account [22]. From Fig. 15, the maximum power density of the buck rectifier assuming the GaN bi-directional transistor was $13.7 \mathrm{~W} / \mathrm{cm}^{3}$ and the power density of the boost rectifier using GaN-HEMT was $12.4 \mathrm{~W} / \mathrm{cm}^{3}$. The buck rectifier with the GaN bi-directional transistors has the potential to accomplish higher power density than the boost-rectifier because the influence of the power devices is negligible and the effect of the passive components becomes obvious.

\section{Conclusions}

GaN buck-rectifier was proposed to achieve higher power density in the ISOP-IPOS converter-based dc distribution system. The characteristics of the ISOP-IPOS converter-based dc distribution system were introduced and the feature of the buck-rectifier was described. Availability of the GaN power device for the buck-rectifier was also verified quantitatively 
taking the theoretical limit for the on-resistance and the switching behavior into account. Design consideration for the GaN buck-rectifier was carried out, and the theoretical power density and the efficiency were evaluated. This design showed the availability of the buck rectifier to achieve higher power density compared with the commonly utilized boost-rectifier.

The ISOP-IPOS converter-based dc distribution system takes full advantage of the buck-rectifier and the rectifier using GaN devices contributes to realizing higher power density de distribution system.

\section{References}

[1] Schmidt, R. R., Belady, C., Classen, A., Davidson, T., Herrlin, M. K., Novotny, S., and Perry, R. 2004. "Evolution of Data Center Environmental Guidelines." ASHRAE Transactions 110 (1): 559-66.

[2] Ministry of Internal Affairs and Communications. 2014. "2014 White Paper Information and Communications in Japan.” Ministry of Internal Affairs and Communications.

[3] Sugiyama, Y. 2011. "Green ICT toward Low Carbon Society-Green R \& D Activities in NTT.” Presented at the 4th International Workshop on Green Communications, Kyoto, Japan.

[4] Yamasaki, M., Kanai, T., Mino, M., and Ohashi, H. 2011. "Potentialities and Problems of the SiC Devices to Apply Practical Use." Presented at the Japan Industry Applications Society Conference, Okinawa, Japan.

[5] Ninomiya, T., Ishizuka, Y., Shibahara, R., and Abe, S. 2012. "Energy-Saving Technology Using Next-Generation Power Electronics." In Proceedings of the IEE (Institution of Electrical Engineers)-Japan Industry Applications Society Conference, I15-20.

[6] Hayashi, Y. 2013. "Multi-converter Approach to Higher Power Density DC-DC Converter for 380 V DC Distribution System.” JEPE (Journal of Energy and Power Engineering) 7 (7): 1331-43.

[7] Hayashi, Y. 2013. "High Power Density Rectifier for Highly Efficient Future DC Distribution System.” Journal of EER (Electrical Engineering Research) 1 (3): 49-59.

[8] Morita, T., Yanagihara, M., Ishida, H., Hikita, M., Kaibara, K., Matsuo, H., Uemoto, Y., Tanaka, T., and Ueda, D. 2007. “650 V $3.1 \mathrm{~m} \Omega \cdot \mathrm{cm}^{2}$ GaN-Based Monolithic Bidirectional Switch Using Normally-Off Gate Injection Transistor." In Proceedings of the IEEE (Institute of Electrical and Electronics Engineers) International Device Meeting, 865-8.

[9] Babasaki, T., Tanaka, T., Nozaki, Y., Tanaka, T., Aoki, T., and Kurokawa, F. 2009. "Developing of Higher Voltage Direct-Current Power-Feeding Prototype System." Presented at the INTELEC (International Telecommunications Energy Conference), Incheon, Korea.

[10] Tolbert, L. M., Ozpineci, B., Islam, S. K., and Chinthavali, M. S. 2003. "Wide Bandgap Semiconductors for Utility Applications." In Proceedings of the IASTED (International Association of Science and Technology for Development) International Conference on PES (Power and Energy Systems) 2003, 317-21.

[11] Kudoh, Y., Mizutani, K., Otsuka, N., Takahashi, S., Inamori, M., Yamagiwa, H., Morita, T., Ueda, T., Tanaka, T., Ueda, D., and Morizane, T. 2014. "Single to Two-Phase Matrix Converter Using GaN-Based Monolithic Bidirectional Switch for Driving Symmetrical Two-Phase Motor." In Proceedings of the IEEE ECCE (Energy Conversion Congress and Exposition), 3186-91.

[12] Takao, K., Irokawa, H., Hayashi, Y., and Ohashi, H. 2006. "Novel Exact Power Loss Design Method for High Output Power Density Converter." In Proceedings of the 37th IEEE PESC (Power Electronics Specialists Conference), 2651-5.

[13] Liu, Z., Huang, X., Lee, F. C., and Li, Q. 2013. "Simulation Model Development and Verification for High Voltage GaN HEMT in Cascode Structure." In Proceedings of the IEEE ECCE (Energy Conversion Congress and Exposition), 3579-86.

[14] Zhang, W., Xu, Z., Zhang, Z., Wang, F., Tolbert, L. M., and Blalock, B. J. 2013. "Evaluation of 600 V Cascode GaN HEMT in Device Characterization and All-GaN-Based LLC Resonant Converter." In Proceedings of the IEEE ECCE (Energy Conversion Congress and Exposition), 3571-8.

[15] Kolar, J. W., Biela, J., and Miniböck, J. 2009. "Exploring the Pareto Front of Multi-objective Single-Phase PFC Rectifier Design Optimization-99.2\% Efficiency vs. $7 \mathrm{~kW} / \mathrm{din}^{3}$ Power Density." In Proceedings of the IEEE 6th IPEMC (International Power Electronics and Motion Control Conference), 1-21.

[16] Ohashi, H. 2006. "Research Activities of the Power Electronics Research Center with Special Focus on Wide Band Gap Materials." In Proceedings of the 4th International CIPS (Conference on Integrated Power Systems) 2006, 1-4.

[17] Hayashi, Y., Takao, K., Shimizu, T., and Ohashi, H. 2007. "High Power Density Design Methodology." In Proceedings of the 4th PCC (Power Conversion Conference), 569-74.

[18] Hayashi, Y., and Yamasaki, M. 2010. "Optimal Design of a High Density Back-End Converter for $400 \mathrm{~V}$ DC Distribution System." In Proceedings of the EPE-PEMC 
(International Conference on Power Electronics and Motion Control), T6-(40-45).

[19] Iyasu, S., Shimizu, T., and Ishii, K. 2006. "A Novel Inductor Loss Calculation Method on Power Converters based on Dynamic Minor Loop.” IEEJ Transactions on Industry Applications 126 (7): 1028-34.

[20] Kim, K., and Shimizu, T. 2007. "Dynamic Iron Loss Measurement Method for an ac Filter Inductor on a PWM Inverter." In Proceedings of the 12th European Conference on EPE (Power Electronics and Applications) 2007, 1-9.
[21] Tsukuda, M., Omura, I., Domon, T., Saito, W., and Ogura, T. 2005. "Demonstration of High Output Power Density (30 W/cc) Converter Using $600 \mathrm{~V}$ SiC-SBD and Low Impedance Gate Driver." In Proceedings of the 2005 IPEC (International Power Electronics Conference), 1184-9.

[22] Hayashi, Y., Toyoda, H., Ise, T., and Matsumoto, A. 2015. "Contactless de Connector based on GaN LLC Converter for Next Generation Data Centers." In Proceedings of the IEEE Transactions on Industry Applications, 1-10. 